THE INTERNATIONAL

REVIEW OF RESEARCH IN

OPEN AND DISTANCE LEARNING

\title{
Challenges of Virtual and Open Distance Science Teacher Education in Zimbabwe
}
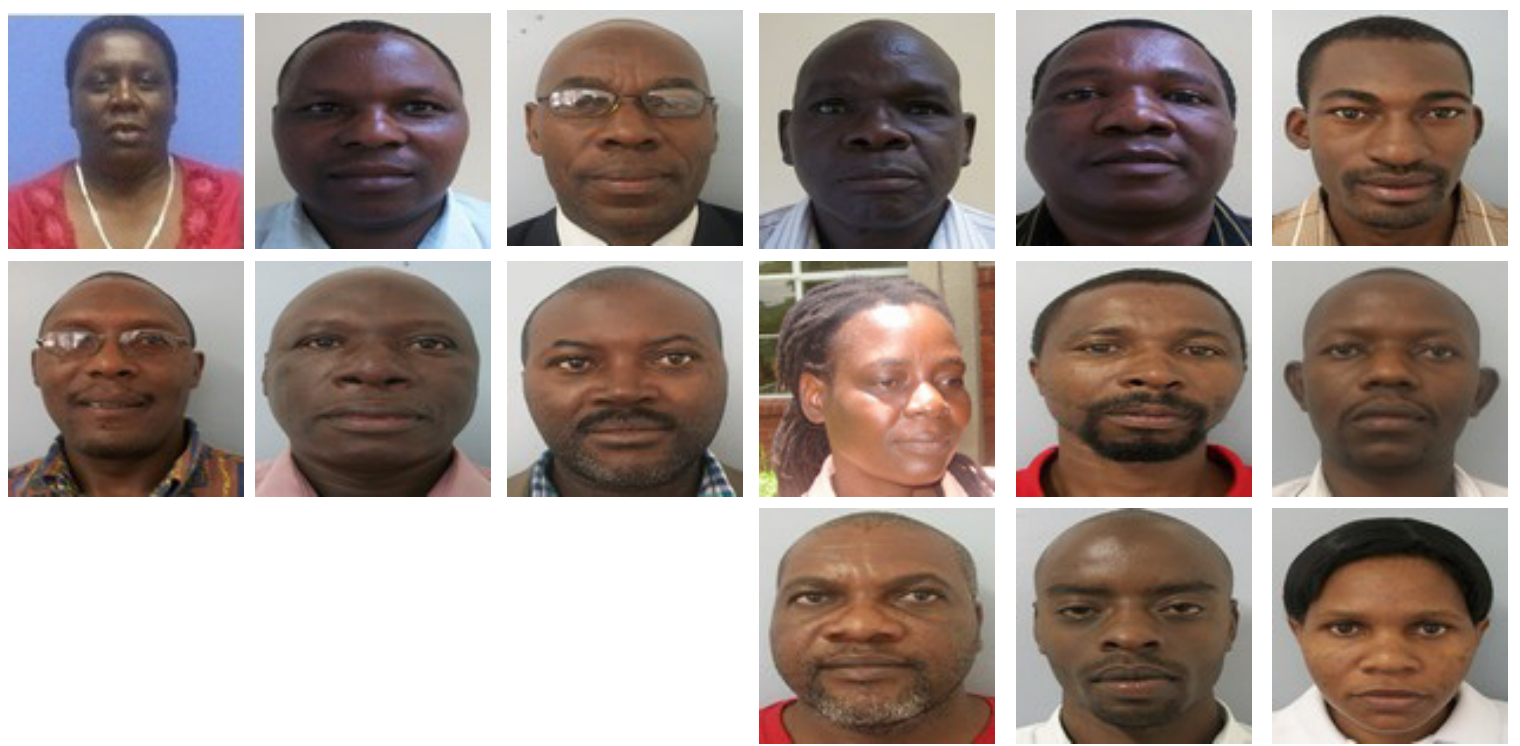

Vongai Mpofu, Tendai Samukange, Lovemore M Kusure, Tinoidzwa M Zinyandu, Clever Denhere, Nyakotyo Huggins, Chingombe Wiseman, Shakespear Ndlovu, Renias Chiveya, Monica Matavire, Leckson Mukavhi, Isaac Gwizangwe, Elliot Magombe, Munyaradzi Magomelo, and Fungai Sithole Bindura University of Science Education (BUSE), Zimbabwe

\section{Abstract}

This paper reports on a study of the implementation of science teacher education through virtual and open distance learning in the Mashonaland Central Province, Zimbabwe. The study provides insight into challenges faced by students and lecturers on inception of the program at four centres. Data was collected from completed evaluation survey forms of forty-two lecturers who were directly involved at the launch of the program and in-depth interviews. Qualitative data analysis revealed that the programme faces potential threat from centre-, institution-, lecturer-, and student-related factors. These include limited resources, large classes, inadequate expertise in open and distance education, inappropriate science teacher education qualifications, implementer conflict of interest in program participation, students' low self-esteem, lack of awareness of quality parameters of delivery systems among staff, and lack of standard criteria to measure the quality of services. The paper recommends that issues raised be addressed in order to produce quality teachers.

Keywords: Open distance learning; lecturer; science education; virtual learning 


\section{Background}

The Millennium Development Goal (MDG) of Education for All (EFA) is clear testimony that education is recognized as a key development concern. However, the realisation of the EFA goal is threatened by several challenges faced by the education sectors across the globe. One of the major challenges facing the education sector is the severe shortage of science teachers, particularly in developing countries. UNESCO (2007) estimated that between 15 and 35 million new teachers are required globally by 2015; 25\% of this global teacher demand is needed in Africa. This high teacher demand has been created mainly by HIV/AIDs attrition and out-of profession teacher migration (UNESCO, 2008).

In Zimbabwe, the economic meltdown of the past decade has triggered one of the worst episodes of technical skills drainage (Chetsanga, 2001; Nyathi, 2010). Science teachers mainly have migrated to other countries in great numbers in search of better working conditions. This has exacerbated the major obstacle in science education in Africa and particularly Zimbabwe in an era when it has been recognized that teacher education lies at the heart of all development (Teferra \& Skauge, n.d., cited in Thakrar, Zinn, \& Wolfenden, 2009). The need to train large numbers of science teachers in Zimbabwe has never been more critical than now. In Zimbabwe this challenge is amplified by the significant numbers of untrained science teachers currently deployed in schools as relief teachers. These relief teachers need access to professional training opportunities urgently.

Bindura University of Science Education (BUSE) is the sole institution in Zimbabwe whose name carries the mandate of science education. It was established as Bindura University College of Science Education (BUCSE) in 1996 to replace the then just ended ZimbabweCuba science teacher training programme. Since then, the University enjoyed a steady increase in the science student teacher enrolment up to 2003. Thereafter, the science student teacher enrolment went down drastically to unsustainable levels by 2009. This scenario has threatened the University's fulfilment of its mandate. Upon recognising that the large numbers of trained science teachers the nation currently needs cannot be achieved through traditional conventional training, BUSE launched an institutionally born intervention project named Virtual and Open Distance Learning (VODL) in Mashonaland Central Province. This national programme was initially started in August 2010 at four centres covering five districts of Mashonaland Central Province.

The VODL programme goal is to train postsecondary school students and Certificate/Diploma in Education holders to attain diplomas or degrees in Science Education. The students recruited in the VODL programme include practicing science teachers (relief and nongraduate) and nonpractising people with prerequisite qualifications who had no access to university education. Deterrents to university teacher education include high entry requirements and high cost of education in an era when Zimbabwe has undergone difficult economic times for more than a decade. The project has been initiated at a time when every nation is in pursuit of EFA (Thakrar et. al, 2009), making it quite significant. The VODL programme is guided by the assumptions of taking university education to the doorstep of the student at an affordable cost and factoring in the bridging aspect to students who meet 
the minimum entry requirements for our degree programmes but without ordinary-level mathematics.

\section{Statement of the Problem}

VODL is a research and development based project designed to meet the high demand of science teachers in Zimbabwe by extending access to science teacher education. Although there have been previous studies on distance education in Zimbabwe and other nations, the unique focus of the VODL project on science teachers calls for empirical evidence that explores the perceptions of students and lecturers of the programme. The study is guided by the following three questions:

1. What are the challenges of the VODL project?

2. What are the sources of these challenges?

3. How can these challenges be overcome?

\section{Significance of the Problem}

The findings of the study are important to BUSE as the proprietor of the programme, in view of Kirk and Dembélé's (2007) caution that short-term responses to teacher shortages can ensure that every classroom has a teacher but raise concerns about their impact on the quality of teaching and learning. Therefore, the study sought to inform programme stakeholders on challenges to expect and enable empirically informed decisions on implementation strategies. Furthermore, the study would enrich the existing theory and knowledge base on distance learning, and in particular contribute towards the literature base on open and distance science teacher education in Zimbabwe and the world at large.

\section{Research Methodology}

\section{Context of Study}

The study was conducted in August 2010 at the four centres during the three-week residential session of the programme launch. The period was university vacation and school holiday. Three of the centres are high schools established as district VODL centres. The other centre is a youth training institution. As a BUSE initiative, the programmes and courses offered are under the auspices of the Faculty of Science Education (FSE). Centre coordinators are responsible for centre administration and report to the programme coordinator. Teaching services were offered by lecturers from the FSE and the Faculty of Agriculture and Environment Science (FAES) at BUSE. A cohort of 1,296 students pioneered in the programme. During semester one of block one (S1B1) the students attended a three-week learner support residential session. The balance of the semester was to be covered in the next school holiday block referred to as S1B2 in December 2010. During the residential session, students attended lectures and consulted their lecturers from Monday to Saturday. 
Students did assignments and in-class tests which contribute to their coursework. At the end of residential session they received assignments to work on during school time.

\section{Research Design}

A mixed methodology research paradigm was adopted in this study for complementary purposes (Gay \& Airasian, 2000) and to capture the different facets of the study (Sandelowski, 2000).

\section{Participants}

All 42 lecturers who were involved in the teaching of the residential session participated in this study.

\section{Data Collection}

Paper and pencil survey, interviews, and document analysis were the different methods triangulated in the collection of data. This was done in line with Creswell's (2007) contention that triangulation is important because the methods in data collection complement each other in such a way that overlapping and different facets of the phenomena under study emerge. This ensures high probability of the trustworthiness of the findings.

A total of 42 participants completed self-designed and administered survey forms in the third week of the residential session. The survey instrument consisted of semistructured questions. The participants were asked to complete the survey and their feedback was guaranteed confidentiality.

Open-ended interviews with six identified key informants were conducted. The open nature of the interviews allowed probing and assessment of the participants' views and feelings. The duration for the interviews was between 20 to 30 minutes. Interview discussions were tape-recorded to capture the audio discussions. These allowed the researcher to gain indepth meanings from the nonverbal cues which were captured by means of field notes.

Documents analysed included the University Act, programme regulations, programme minutes, supervision reports, centre reports, teaching timetable, and lecturers' and students' records.

\section{Data Analysis and Presentation}

The data from the survey was analysed using Statistical Package for Social Sciences SPSS version 17. Interviews were transcribed and the resultant data was content analysed to describe and interpret their meaning and then organized into emerging themes (Walliman \& Buckler, 2008). All data from the documents, interviewees, and survey respondents were compared, integrated, and pooled together to address the research questions. The findings are presented in a descriptive form supported by some descriptive statistics and direct extracts from field notes and interview transcripts. The data is presented in the form of tables, charts, and graphs. 


\section{Findings}

The findings of this study revealed the following challenges: centre-, institution-, staff- and student-related.

\section{Centre Challenges}

The greater parts of Mashonaland Central Province are rural areas. Three of the VODL centres were connected to electricity, but the power was not always available 24 hours per day, due to power outages. The centres had electric generators but the centre budgets could not sustain the expensive diesel fuel to power the machines throughout the working day. The fourth centre had a vandalised electrical grid. However, this centre was able to run its generator for the three-week residential session daily. The problem of electricity created problems of integration of ICT tools (e-mail, fax, Internet, television, radio, etc.) into the VODL programme. The basic communication infrastructure to enable VODL to make use of these technologies is not in place at the centres.

The residential session centres currently lack enough laboratory space to cope with the demand of practical subject training. Only one centre (25\%) has physics, chemistry, computer science, and biology laboratories. These laboratories have a carrying capacity of $15-25$ students per session. Though the buildings are in place, they lack equipment, apparatus, and consumables for practicals. Limited electricity supply meant that teaching and learning was done without the support of ICT most of the time. Poor physical infrastructure and limited resources promoted the use of traditional teaching approaches. No practical work was conducted in all courses, except a practical component for computer science at one centre during the first residential session, divorcing theory from practice. The first residential session promoted procedural learning rather than conceptual learning. Other resources which were in short supply included reading material, stationery, and furniture.

The challenge of resource limitation was summed up by one of the interviewees who lamented that,

We were excited about the programme. However, our first residential session had lots of things need to be taken into consideration for the program to be a success. These include lack of resources for practical work, limited teaching resources like stationery, reading material for students and furniture. Imagine, some of the classrooms we used as lecture rooms did not even have boards to write on. Library facilities had limited text books and some of them irrelevant. I had no preparation time as I was loaded during the day and no electricity for lighting at night.

\section{Institution Challenges}

The majority (93.3\%) of lecturers cited that too many courses were offered during S1B1. Di- 
ploma students were enrolled in the following options: Biology, Geography and Agriculture (BGA), Mathematics, Physics and Computer Science (MPCs) and then Chemistry, Physics and Biology (CPB). All students registered for education courses which included educational foundations (Philosophy, Sociology, and Psychology) and Communications. Teaching practice referred to at this institution as Applied Science Education (ASE) was to be introduced. Candidates without an ordinary level mathematics pass were offered a bridging course. This translated to a diploma student doing a total of nine courses without a bridging course and ten courses if a mathematics bridging course was included (six courses per combination, namely three education courses and one ordinary-level mathematics bridging course).

All participants (100.0\%) concurred that this residential session was short, packed with a congested timetable which ran from 7:00 a.m. to 5:30 p.m. from Monday through Saturday. There was a half hour and a one hour tea and lunch break per day. The major challenge for the lecturers was overload with some teaching six hours per day for six days a week. The centres were paired to enable the teaching of same courses at two centres for oneand-a-half weeks per centre and exchange thereafter. For example, for diploma courses in chemistry at two paired centres, General Chemistry was taught at one centre, whilst at the centre paired to it, Laboratory Techniques was being taught. This caused comprehension problems for the students who started with a higher level course. On average $35 \%$ of the theory course content was covered during the $\mathrm{S} 1 \mathrm{~B} 1$ residential session as reported by the majority $(67.7 \%)$ of the lecturers. No planning for practical work was done as reflected by the absence of practical work slots on the timetable and as a result no practical work was done.

The VODL curriculum (courses on offer) was adopted from the conventional programmes and courses. This means that the curriculum was not adapted to the needs of the programme.

One interviewee offered the following reflection:

The departmental individualistic approach to teaching made it difficult for students to understand abstract things, especially considering their background. However, this can easily be overcome if we harmonize courses where possible. Those that communicate (courses that are related) should be combined at the same time. In some cases Diploma courses we offered are conventional undergraduate courses.

The implication is that students were challenged by cognitive overload which refers to "mental blackout" as a result of learning new, varied, and complex content, which challenges conceptual understanding of the material presented (Tyler-Smith, 2006). Furthermore, students had very little time to access library services during the day. During the night students had no time to access the library due to power outages. 


\section{Staff Challenges}

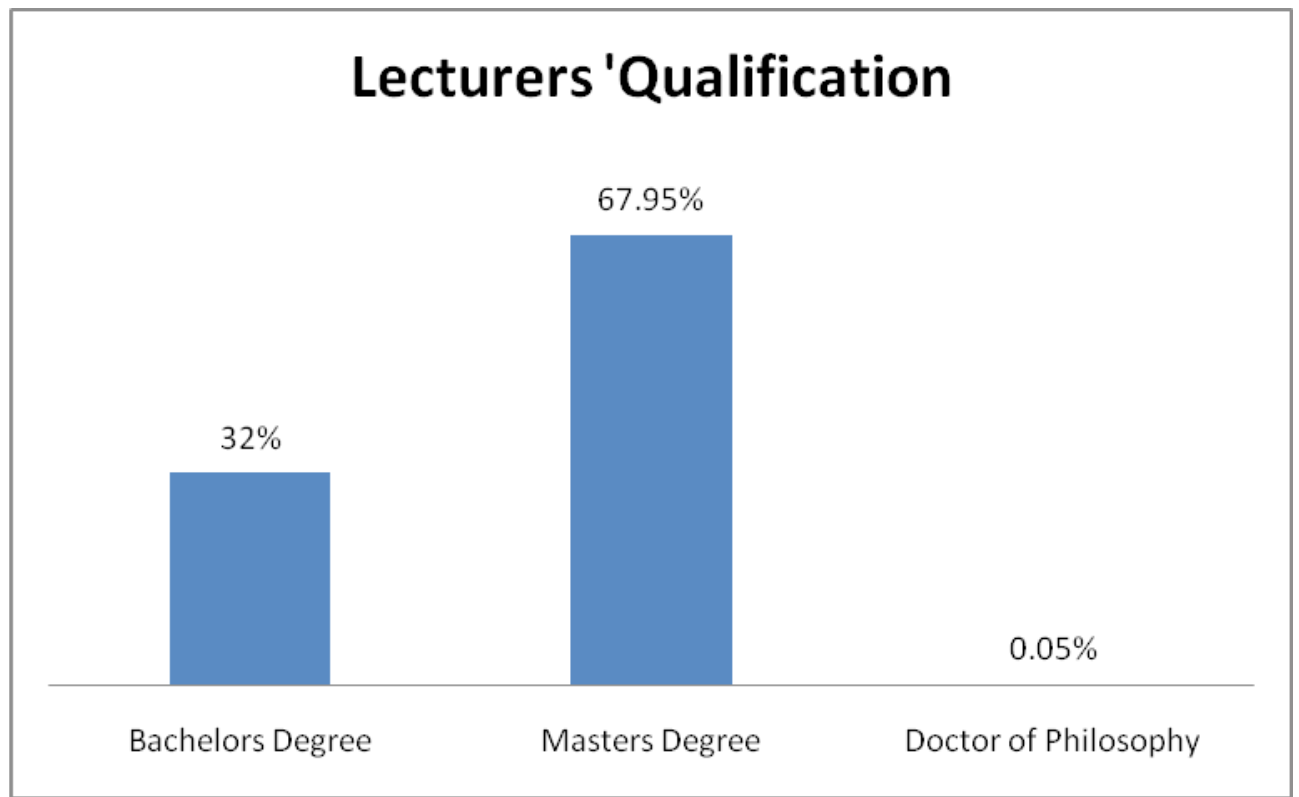

Figure 1. Showing lecturers' qualifications.

The majority (90.0\%) of lecturers who participated in the S1B1 are BUSE FSE employees, whilst the remaining proportion was engaged on a part-time basis. Approximately, $32 \%$ of the first residential session lecturers are first-degree holders in pursuit of master's degree qualifications, about $67.95 \%$ have master's degrees, and a significantly smaller number (0.05\%) are $\mathrm{PhD}$ holders.

\section{Evaluation of Teaching Areas}

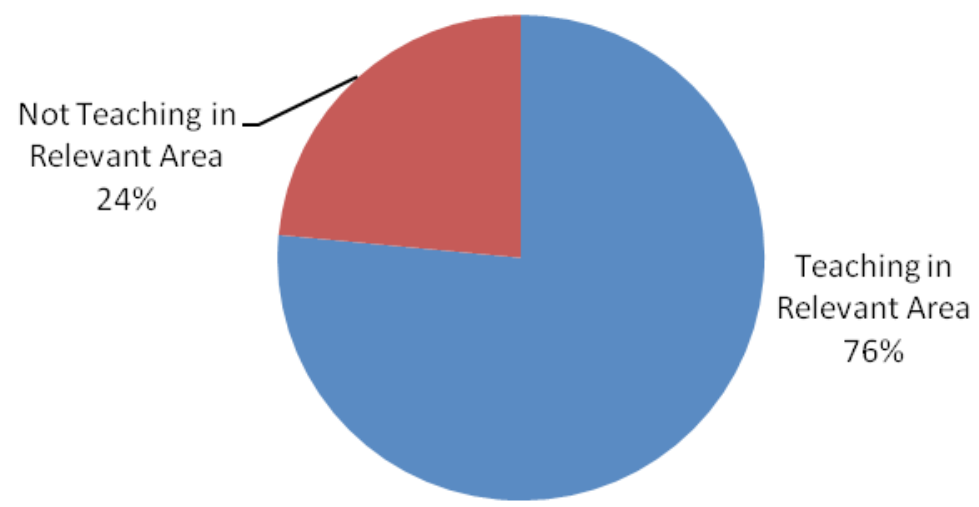

Figure 2. Showing an evaluation of teaching areas. 
Quite a significant proportion of lecturers (23.5\%) was teaching in areas not quite relevant to their area of specialisation. In addition, all the lecturers (100.0\%) have a full load of conventional teaching. The foresaid leads to underperformance of duties as a result of time constraints and course knowledge limitations.

Thirty-two percent of lecturers have not been trained as science educators. This insufficiency was reflected in the lack of quality instruction as reported by one interviewee:

Some lecturers had content depth and coverage problems especially to teaching diploma students. Some of the students have already said gejo ngaridzike (meaning teaching content should be adjusted to match the students' learning styles and the study level).

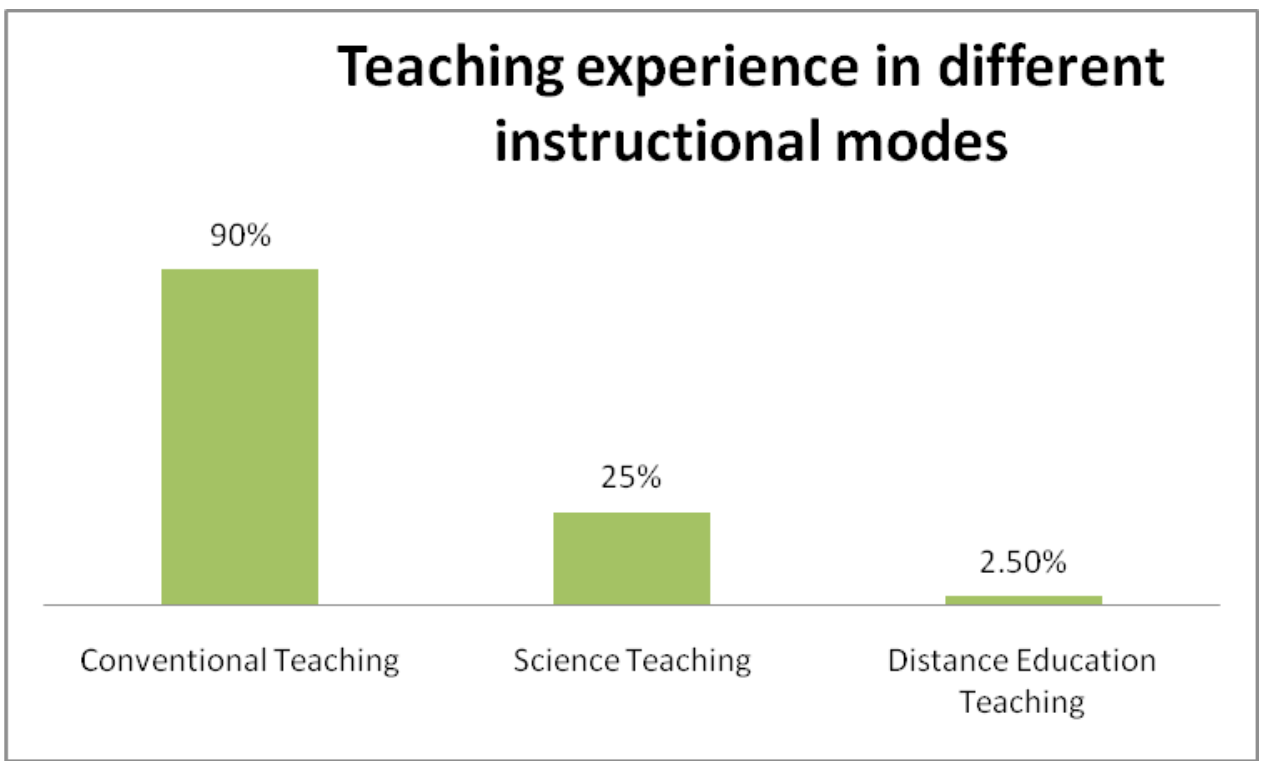

Figure 3. Showing the teaching experience of the lecturers in different instructional modes.

Most of the lecturers (90.0\%) have 1-3 years university conventional teaching and 97.5\% have no experience in distance education. Seventy-five percent of those who lectured educational foundation courses have no science-related background. Insufficient university conventional teaching experience, limited pedagogical knowledge, and limited science qualification promoted the use of traditional classroom practices which are not appropriate for quality learning in the programme. This may create frustrations in students and eventually lead them to drop out.

The nation's current economic situation and its effects on most Zimbabweans have made the cost of living very high. University lecturers in Zimbabwe earn far below their counterparts in Southern African Development Community nations' universities. The regional salary levels which are notably above the average regional poverty datum level motivate them or raise their professional dedication. It is likely that most of the lecturers have joined 
lectureship in order to get better pay. More so, the participation in the VODL programme, for the majority, was dysfunctionally construed as an opportunity to make money. One of the interviewees is quoted as saying,

The lecturers were excited, especially with the idea of getting an extra allowance. U-um it's really just disappointing that some of them were not content with the allowance. They sold notes to the students. I don't know what is wrong. Why could they not bear with the economic situation of the VODL students?

The other challenge associated with the aforementioned drawback is the absence of programme quality assurance benchmarks and systems.

\section{Student Challenges}

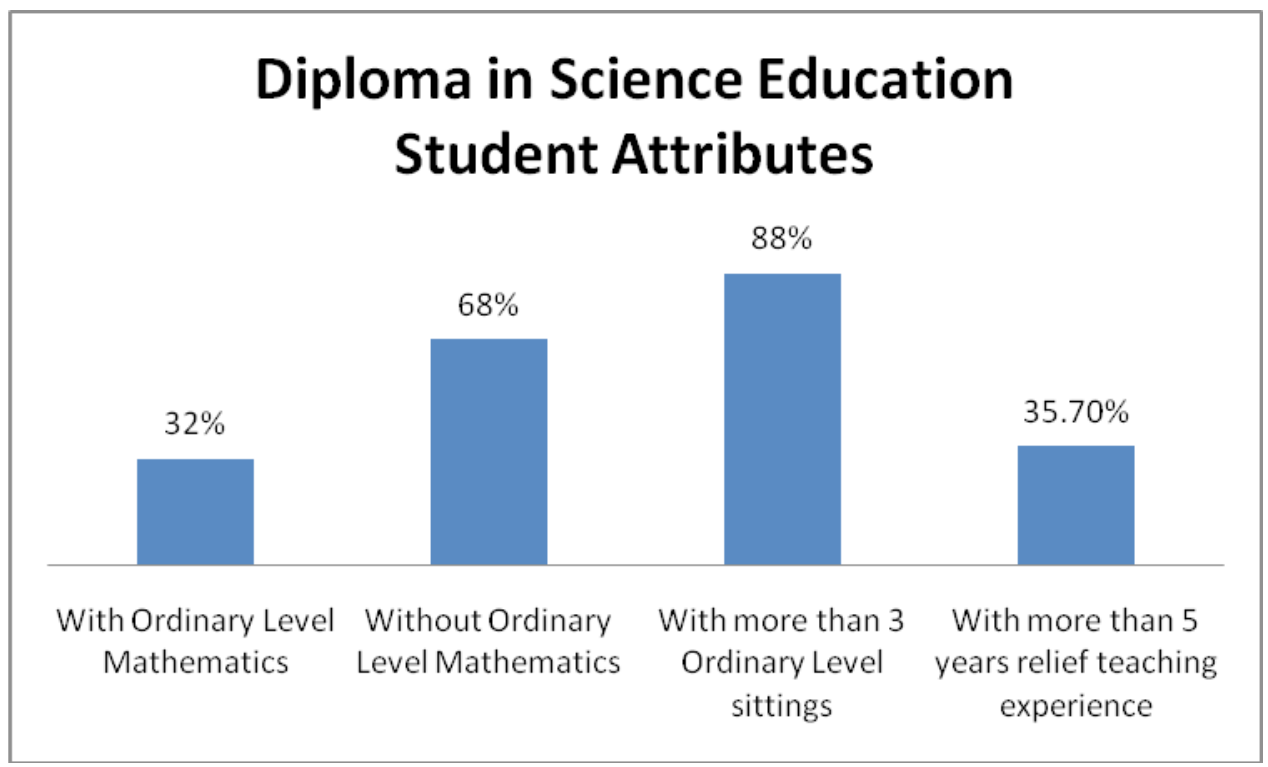

Figure 4. Showing Diploma in Science Education students' attributes.

The majority (76.5\%) of the students are enrolled in the Diploma in Science Education (DipScED) VODL programme. The educational background of DipScED students is a minimum of five O-level passes including a science subject and English language. Sixty-eight percent of these students do not have a pass in O-level mathematics and are doing it as a bridging course. Most (88 \%) of the DipScED students have more than three O-level sittings. Such an educational background results in feelings of low self-efficacy, stress, and cognitive overload, especially where complex and diversified content is presented within a short space of time. Such effects are worse in learners at advanced ages, which ranged from 23 - 54 years with several of them having a primary-level relief teaching experience; $35.7 \%$ had above five years of relief teaching experience. This observation is substantiated by what one of the interviewees said: 
The background of most students contributed much to lapses and time wastage. Their academic level and stamina required caused us to go down to low levels and then take them up gradually. But this was impossible considering the amount of content we needed to cover during the residential session.

The Bachelor of Science in Education (BScEd) students (23.5\%) have better O-level results and higher qualifications, with either two subjects at Advanced Level or a certificate/ diploma in secondary or primary education, than the DipScED students. However, such a diversified background is problematic to instruction taking cognisance of the weak pedagogical content knowledge of the lecturers.

Over $75.0 \%$ of the students enrolled in the first VODL cohort are contract teachers on relief teaching in primary and secondary schools. The remaining proportion of the students was unemployed or employed in nonteaching jobs and a variety of unskilled jobs. Their main purpose for enrolling in the programme was conveyed in one of the interviews:

You see relief teaching is a source of income for those who have not done so well at O-level. They consider it as a last resort as the Ministry is in high demand of teachers. This programme to them guarantees continuous employment as they do not have to queue for it on termly basis.

The preceding expression evidences a high probability that these students, especially the DipScED ones, have turned to the programme and teaching in particular for the employment opportunities and the regular income it offers at the present moment rather than for professional reasons. The drawback associated with such a scenario is the resulting poor attitudes, including lack of commitment, resourcefulness, self-discipline, and selfmanagement, among others, which may cause students to drop out when the going gets tough.

Other student-related problems include financial costs of study, disruption of family life, lack of stakeholder support, and rural operating environment.

\section{Discussion, Implications, and Recommendations}

Problems encountered during the $\mathrm{S} 1 \mathrm{~B} 1$ residential session were many and varied. There are several ways of categorising these challenges. One way adopted in this study is the categorising of the challenges into centre-, institution-, staff- and student- related. Whilst the residential session is meant to provide student-lecturer face-to-face interactive opportunities, which are lacking in most distance education programmes, it becomes imperative that the centres' physical infrastructures, equipment, and furniture be supportive to the intensive learning. Institutional support helps to alleviate distance learners insecurities 
related to centre context (Knapper, 1988). The literature is rich with the problems of attrition associated with distance learning. Whilst numerous studies cite myriad and complex reasons for attrition, Simonson et al., (2000) refer to Garland's ethnographic study finding that a poor learning environment and a lack of time are the major determinant to high attrition rate. The current resource statuses of residential session centres are likely to depress the enrolled students and cause attrition as well as deter prospective program students. Though the programme has the potential to sustain itself, at this infant stage it requires substantial funding to inject it with the highly needed resources. The management needs to appraise all the critical stakeholders and partner with them in the programme in order to build a strong resource base. The virtual component of the programme calls for intensified efforts to integrate ICT in learning.

The resource-constricted conventional curriculum adapted to the VODL programme presents a number of study mode incompatibility problems The conventional content curriculum demands, limited resources, lecturers' limited pedagogical content knowledge, and short residential session, among others, orient lesson delivery towards traditional teaching instruction. A research study by Sikwibele and Mungoo (2009) concurs with the foresaid concern that lecturers who are trained for conventional instruction at primary, secondary, or tertiary educational settings lack distant education teaching experience and use pedagogy that borrows heavily from traditional classroom practices. Traditional teaching approaches promote rote learning and develop cognitive overload and resistance in students. According to Rubanju (2008), use of traditional teaching strategies defeats the purpose of context-based learning. In view of the foregoing discussion, all those involved in the VODL teacher education programme should be equipped with skills and knowledge of productive distance education teaching. The institutions have to provide frameworks for VODL operations to curb unethical practices. Restructuring of the ways in which teaching and learning are delivered and regular curriculum review to suit the nature of the programme becomes fundamental for its goal to be realised.

Generally, distance learners, more often than not, have insecurities about learning grounded in personal, residential session, centre, and institutional factors (Knapper, 1988). The centre, institution-, and staff-related VODL programme challenges revealed in this study added pressure on the student. Such pressure often results in dropouts (Sweet, 1986). According to Campbel (1992) as cited by Nyondo (n.d.), age, maturity, and learning styles impact the learning process of the distant student. In this regard Yusuf (2006) emphasises proper selection of learners with desirable characteristics for distance learning programmes. Therefore, overcoming distance learning pressure is heavily dependent on individual characteristics. The characterisation of the VODL students presented in this study reflects that they need a lot of economic, social, and resource support if they are to withstand the programme pressure. It becomes imperative that these students be attached to study mentors to offer them guidance, time management techniques, and initiatives to encourage them to progress (Huang, 2000, cited by Yusuf, 2006).

The success of the programme heavily lies with issues of monitoring and evaluation (ME) of the programme for quality assurance. Valid and reliable ME performance frameworks 
should be in place, known, and well understood by all programme stakeholders and then rigorously applied in the implementation of the VODL programme. This will not only ensure a quality product but market the programme for possible expansion beyond Zimbabwean boarders.

\section{Conclusion}

The VODL programme has incredible potential to supply secondary schools in Zimbabwe and beyond with the much needed large numbers of science educators. The complementary aspects of student-lecturer face-to-face interaction during residential sessions and learner independence and responsibility in between residential sessions make this particular programme innovative to science teacher education. These unique features provide a basis for the development of theoretical models for quantity and quality science educator demanddriven programmes. The programme also provides an effective step towards democratisation of science education. Further, it is a basis for providing science teacher education through lifelong learning opportunities. If successfully implemented, this VODL mode of science teacher education programme has unique features that other nations may incorporate in their science educator programmes as a way of addressing the science educator shortage. This is in line with the recommendation made by Osborn and Dillion (2004). However, the University, residential session, institution, lecturer, and student challenges highlighted in this study have serious repercussions on the quality of the programme and need to be addressed. The VODL programme goals will be achieved if proper steps to address the challenges revealed in this study are taken. The steps to be taken may include the following: setting up induction, orientation, and in-service programmes for lecturers; recruitment of full-time course coordinators with relevant experience and expertise; provision of weekend sessions for both academic and nonacademic dialogues to cater for students' learning needs. Finally, there is a need to put into place research-driven curriculum modification to enhance the quality of the programme. 


\section{References}

Kirk, J., \& Dembélé, M. (2007). More and better teachers needed: Achieving quality education for all. Id21 Insights, 6. Retrieved from http://www.id21.org/insights/insights-edo6/insights edn 6.pdf

Knapper, C. (1988). Lifelong learning and distance education. American Journal of Distance Education, 2(1), 63-72.

Nyondo, C., (not dated). Socioeconomic factors affecting distance learning in Papua New Guinea.

Rubanju, A. C. G. (2008). Quality challenges in higher education institutions in Uganda. Institute for Educational Research, University of Oslo. Retrieved from http://www. uv.uio.no/studentliv/isne/assets/docs/Unit\%201\%20paper\%20assignment.doc

Sikwibele, A.L., \& Mungoo,J.K. (2009). Distance learning and teacher education in Botswana: Opportunities and challenges. International Review of Research and Open Distance Learning, 10(4).

Sweet, R. (1986). Student drop-out in distance education: An application of Tinto's model. Distance Education, 7, 201-213.

Thakrar, J. Zinn, D., \& Wolfenden, F., (2009). Harnessing open educational resources to the challenges of teacher education in Sub-Saharan Africa. International Review of Research in Open and Distance Learning, 10(4). Retrieved from http://www. irrodl.org/index.php/irrodl/article/view/705

Tyler-Smith, K. (2006). Early attrition among first-time e-learners: A review of factors that contribute to drop-out, withdrawal and noncompletion rates of adult learners undertaking e-learning programmes. Journal of Online Learning and Teaching, 2(2). Retrieved from http://jolt.merlot.org/Vol2 No2 TylerSmith.htm

Yusuf, M. O., (2006). Problems and prospects of open and distance education in Nigeria. Turkish Online Journal of Distance Education, 7(1).

\section{Athabasca University $\mathbf{2}$}

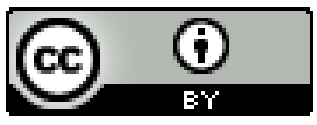

